\title{
A study on plastic waste generation in Aizawl city, Mizoram
}

\author{
Anil Pratap Singh ${ }^{1}$ and Dr.Angom Sarjubala Devi
}

\author{
1,2Department of Environmental Science, Mizoram University, \\ Aizawl, Mizoram-796004, India
}

\begin{abstract}
Plastics waste assessment was carried out during year 2017-20.Maximum plastic waste generation per capita per year was observed in Central locality with $5.56 \pm .99 \mathrm{Kg}$ and least in South locality with $4.34 \pm 1.14 \mathrm{Kg}$. Maximum plastic waste generation per capita per day was found in Central Locality $20.03 \pm 1.76 \mathrm{~g}$ and least in South locality $15.71 \pm 1.61 \mathrm{~g}$. Result of ANOVA analysis shows significant difference among various localities in terms of plastic waste generation per capita per year $\left(\mathrm{F}_{4,10}=20.07, \mathrm{P}<.005\right)$, and plastic waste generation per capita per day $\left(\mathrm{F}_{4,10}=18.33, \mathrm{P}<.005\right)$.Maximum amount of plastic waste/household was generated during winter season with $10.30 \mathrm{Kg} /$ household.Minimum amount of plastic waste/household was generated during rainy season with $8.13 \mathrm{Kg} /$ household. The result of ANOVA test reveals that there was significant monthly variation in household generation of plastic waste during year 2017-18 $\left(\mathrm{F}_{8,664}=3.41, \mathrm{P}<.005\right), 2018-19\left(\mathrm{~F}_{8,664}=3.43, \mathrm{P}<.005\right), 2019-20$ $\left(\mathrm{F}_{8,664}=3.42, \mathrm{P}<.005\right)$.
\end{abstract}

Keywords: waste, plastic waste, waste management, waste generation

\section{Introduction}

In India approximately 9.4 million TPA plastic waste is generated per year, which amounts to 26,000 TPD out of this, about $60 \%$ is recycled, most of it by the informal sector. While the recycling rate in India is considerably higher than the global average of $20 \%$, there is still over 9,400 tonnes of plastic waste which is either landfilled or ends up polluting streams or groundwater resources. While some kinds of plastic do not decompose at all, others could take up to 450 years to break down.

Most common use of plastics is packaging which is discarded after use. Around 50\% of plastic is discarded as waste after single use. Single use plastics (SUP) like cups, plates, straws, stirrers, bottles, food containers are substantial sources of plastic pollution.

Around 8 million tonnes of plastics enters in ocean every year. Microplastics are rising in oceans and is being ingested by marine creatures. Certain chemical are added to make plastics more flexible, fire resistant and durable. These chemical are Polybrominated Biphenyls, Bisphenols, Phtahalate esters etc. once released from plastic, upon degradation these chemicals can have serious health implications thereby affecting reproductive, endocrine system and central nervous system. Unmanaged plastic waste gets littered everywhere destroys aesthetics of place. Solution to present problem can achieved through concerted means of stringent legislations, enhancing collection and recycling, suitably substituting plastics with biodegradable alternatives, raising public awareness and taking up cleanup measures.In light of growing concern over plastic waste problem and lack of reliable data and statistics regarding plastic waste, assessment was doneinvarious localities of municipal area during2017-20

\section{Materials and Methods}

Aizawl the capital of Mizoram is selected as study area. It is located in the northern part of Mizoram at north of the Tropic of Cancer. It is situated on a ridge 3715 feet above the sea level. Aizawl is geographically located at $23^{\circ} 43^{\prime} 59^{\prime \prime} \mathrm{N}$ latitude and $92^{\circ} 43^{\prime} 00^{\prime \prime} \mathrm{E}$ longitude. The total geographical area of Aizawl city is 3,576,000 hectare which is about $16 \%$ of the state area of Mizoram with a population density of about 112 persons per sq. $\mathrm{km}$ as per 2011 census. The population of Aizawl city is 404,054 as per Census 2011 with a decadal growth rate of 24.07 per cent. The city is divided into 19 wards for administrative purposes. The civic administration in the city of Aizawl falls under the jurisdiction of Aizawl Municipal Corporation.

Waste quantification and characterization of plastic waste in residential area focused on measurement of plastic being generated and further assessment of physical categories and chemical characteristics of plastic waste.385 households representing North, South, East, West and Central Aizawl were surveyed during 2017-18,201819,2019-20.Every year survey was conducted for 9 months duration and data was collected monthly, covering 3 seasons Winter (November, December, January),Summer (March, April, May), Rainy (July, August, September).Plastic waste assessment in residential area was conducted according procedure fallowed Thanh et al.,2011.Plastic waste assessment and characterization in residential and commercial area were done according to Plastic waste assessment guidelines established by UNEP (2009),Household survey guidelines (2005) by Department of Economic and Social Affairs while Identification of 
plastic polymer type was done according to procedure established by Harris and Walker, 2010.

\section{Results and Discussion}

Several factors influence the quantity, physical and chemical characteristics of waste generated at various sources. Factors such as employment status, household size, seasons, income level and population influence the variation in the composition of MSW waste streams.One of the major factors leading to variation in the quantity and morphological composition of municipal solid waste is the season. Changes in weather conditions at different seasons in a year affect consumption pattern and human activities and influences the fractions of the waste stream such as plastics, paper, metal, textile and organic waste (Denafas et al., 2014).Seasonal variations in generation of waste have been observed in various studies done previously by Kamran et al.,2015;Gomez et al.,2009;Jadoon et al.,2014;Al Khatib et al.,2010;Zeng.,2005., Gidarakos et al.,2006., Aslani and Taghipou,2018., Denafas et al.,2014). Possible reason for maximum plastic waste/household generation in winter season could be winters being festival season in Aizawl city it is a time when people tend to consume more evidenced by crowded markets, ongoing sales and online shopping at its peak and least plastic waste/household was generated during Rainy season. It has been observed peoples consumption pattern didn't change considerably during survey period (2017-20) as family size, yearly income and attitude and perception remained unchanged. The difference in plastic waste generation observed is due to different demography of various localities $(\mathrm{S}, \mathrm{N}, \mathrm{E}, \mathrm{C}, \mathrm{W})$ as waste generation have been found to depend upon economic status, family size, cultural factors and level of awareness among members different households Buenrostro (2003);Ashley et al.,2006;Agarwal et al.,2013, Rhyner (1992).

Table1. Plastic waste (PW) generated Kg per capita per year in different localities during three years

\begin{tabular}{|c|c|c|c|}
\hline & PW/Capita/Yr & PW/Capita/Yr & $\mathrm{PW} / \mathrm{Capita/Yr}$ \\
\hline Locality & 2017-18 & 2018-19 & 2019-20 \\
\hline South & $4.34 \pm 1.20$ & $4.00 \pm .94$ & $4.66 \pm 1.30$ \\
\hline Central & $5.56 \pm .86$ & $5.47 \pm .82$ & $5.66 \pm 1.30$ \\
\hline West & $4.56 \pm 1.30$ & $4.61 \pm 1.4$ & $4.85 \pm .83$ \\
\hline North & $4.30 \pm .73$ & $4.26 \pm .98$ & $4.59 \pm .95$ \\
\hline East & $4.82 \pm 1.2$ & $4.75 \pm 1.4$ & $4.94 \pm .94$ \\
\hline
\end{tabular}

Table2. Seasonal plastic waste generation $(\mathrm{Kg}) /$ household

\begin{tabular}{|l|r|r|r|}
\hline \multirow{2}{*}{ Year } & \multicolumn{3}{|c|}{ Season } \\
\cline { 2 - 4 } & Winters & Summer & Rainy \\
\hline $2017-18$ & 10.05 & 8.82 & 7.88 \\
\hline $2018-19$ & 10.49 & 9.23 & 8.31 \\
\hline $2019-20$ & 10.37 & 9.14 & 8.2 \\
\hline Total & 30.91 & 27.19 & 24.39 \\
\hline Avg & 10.30 & 9.06 & 8.13 \\
\hline
\end{tabular}

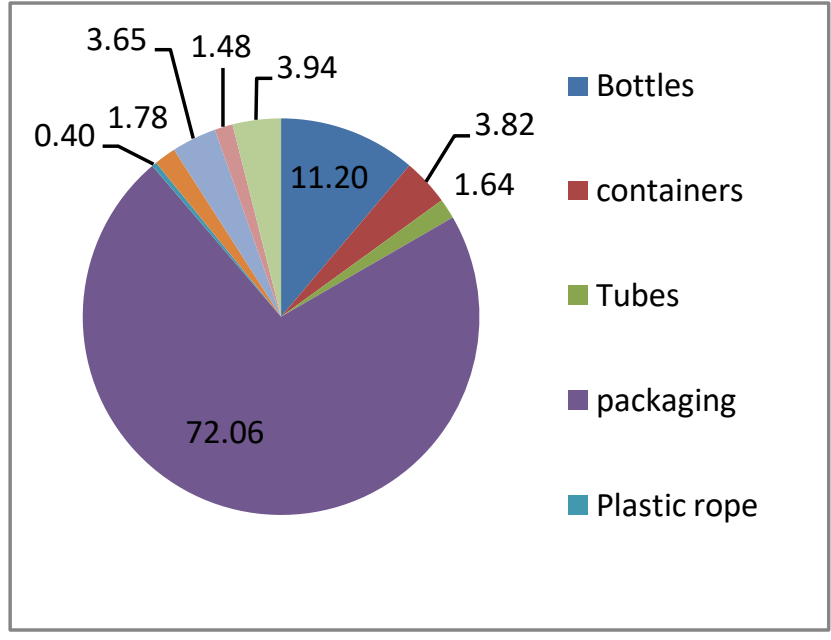

Fig.1 Physical characteristics of plastic waste at residential area $2017-20$

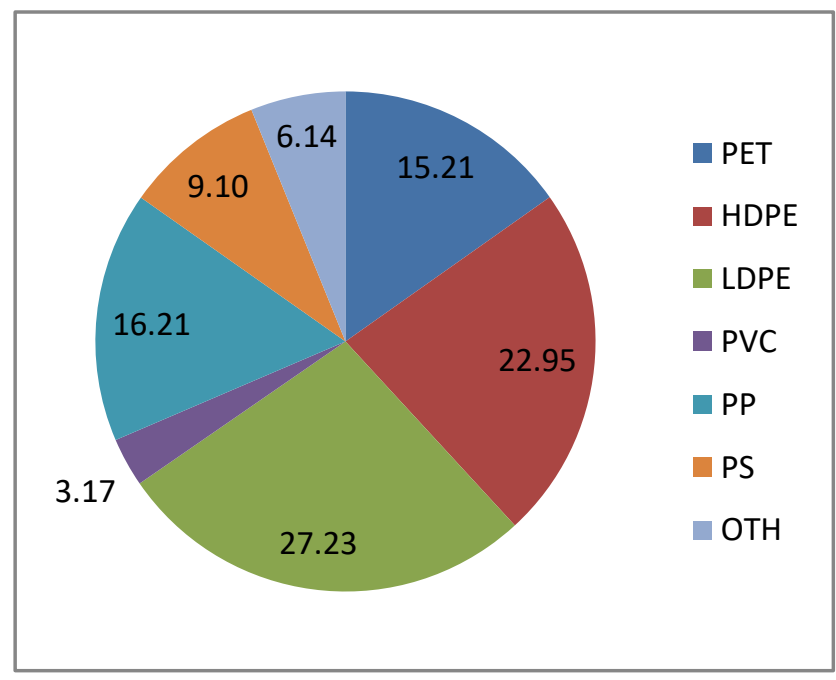

Fig.2 Chemical characteristics of plastic waste at residential during 2017-20

In residential area plastic waste is dominated by packaging material (72.6\%), Bottles (11.20\%), containers (3.82\%)and plastic waste belonged to PET(15.21\%), LDPE(27.23\%), PVC(3.17\%), HDPE(22.95\%), PP(16.21), PS(9.10\%).

\section{Conclusions}

By comparing between the five localities it was observed that during year 2017-18 maximum plastic waste was generated in West locality $(2134.68 \mathrm{Kg})$ and minimum in North locality (2045.94 Kg), during year 2018-19 maximum plastic waste was generated in South locality $(2157.93 \mathrm{Kg})$ and minimum in North locality $(1994.18 \mathrm{Kg})$, during year 2019-20 maximum plastic waste was 
generated in West locality $(2164.70 \mathrm{Kg})$ and minimum in North locality (2040.34 Kg). During 2017-18 central locality generated maximum $5.56 \pm .86 \mathrm{Kg}$ plastic waste/capita/yr while minimum was observed in North locality which generated $4.30 \pm .73 \mathrm{Kg}$ plastic waste /capita/yr.During 2018-19 Central generated maximum $5.47 \pm .82 \mathrm{Kg}$ plastic waste/capita/yr while minimum was observed in South locality which generated $4.00 \pm .94 \mathrm{Kg}$ plastic waste /capita/yr .During 2019-20 central locality generated maximum $5.66 \pm 1.30 \mathrm{Kg}$ plastic waste/capita/yr while minimum was observed in North locality which generated $4.59 \pm .95 \mathrm{Kg}$ plastic waste /capita/yr

\section{Acknowledgments}

Authors are highly grateful to AMC (Aizawl municipal corporation) for granting permission and providing all necessary help to successfully conduct waste survey.

\section{References}

[1]Al-Khatib IA, Monou M, Zahra ASFA, Shaheen HQ,Kassinos D (2010) Solid waste characterization, quantification and management practices in developing countries. A case study: Nablus districtPalestine. J Environ Manag 91(5):1131-1138

[2]Ashley R, Blackwood D, Souter N, Hendry S, Moir J, Dunkerley J et al (2005) Sustainable disposal of domestic sanitary waste. J Environ Eng 131(2):206215

[3]Aslani H, Taghipour H (2018) Seasonal characterization and quantification of municipal solid waste: energy content and statistical analysis. J Adv Env Heal Res 6:34-43

[4]Buenrostro O, Bocco G (2003) Solid waste management in municipalities in Mexico: goals and perspectives. Resour Conserv Recycl 39(3):251-263

[5]Denafas G, Tomas R, Dainius M (2014) Seasonal variation of municipal solid waste generation and composition in four East European cities. Resour Conserv Recycl 89:22-30

\section{ISSN 2455-6378}

[6]Gidarakos E, Havas G, Ntzamilis P (2006) Country report: municipal solid waste composition determination supporting the integrated solid waste management system in the island of Crete. Waste Manage 26:668-679

[7]Gómez G, Meneses M, Ballinas L, Castells F. Seasonal characterization of municipal solid waste (MSW) in the city of Chihuahua, Mexico. Waste Manage 2009;29:2018-24

[8]Jadoon A, Batool SA, Chaudhry MN (2014) Assessment of factors affecting household solid waste generation and its composition in Gulberg Town, Lahore, Pakistan. J Mater Cycles Waste Manag 16:73-81

[9]Kamran, A.; Chaudhry, M.N.; Batool, S.A. (2015)Effects of socio-economic status and seasonal variation on municipal solid waste composition: a baseline study for future planning and development.Environ Sci Eur. 27:16

[10]Practical Guidelines (2005). Department of Economic and Social Affairs,Statistics Division,Studies in Methods Series F No.98. United Nations,New York.pp 255

[11]Rhyner CR (1992) Monthly variations in solid waste generation. Waste Manag Res 10:67-71

[12]Thanh N.P.,Yasuhiro M.,Takeshi F.(2011).Assessment of plastic waste generationand its potential recycling of householdsolid waste in Can Tho City, VietnamEnviron Monit Assess (2011) 175:23-35

[13]UNEP (2009)Converting Waste Plastics In to a Resource Assessment GuidelinesUnited Nations Environmental Programme Division of Technology, Industry and Economics International Environmental Technology Centre Osaka Offi ce2-110 Ryokuchi Koen, Tsurumi-ku Osaka. Japan.PP 73

[14]Zeng Y, Trauth KM, Peyton RL, Banerji SK. Characterization of solid waste disposed at Columbia Sanitary Landfill in Missouri. Waste Manage Res 2005;23(1): 